\title{
SHIFT FROM EDUCATION TO DEVELOPMENT: LEADERS AND COACHES IN SEARCH OF SHARED WISDOM
}

\author{
Julia Choukhno, MA, Nova Terra Coach Training \& Corporate Development, Moscow, Russian Federation, \\ E-mail: jch@novaterracoaching.su \\ Dr. Mikhail Klarin, Laboratory for Didactics (General Theory of Education), Institute for Strategy of Education \\ Development, Russian Academy of Education, Moscow, Russian Federation \\ E-mail: consult@klarin.ru \\ Dr. Tatiana Kosyaeva, Czech Academy of Sciences, Prague \\ E-mail: Tatyana.Kosyaeva@cerge-ei.cz
}

A R T I C L E I N F O
Original Article
Received: November, 10.2016.
Revised: December, 12.2016.
Accepted: December, 15.2016.
doi:10.5937/IJCRSEE1602023C
UDK
371.398
371.134:005.5

Keywords:

developmental paradigm,

wisdom,

wisdom-related values,

coaching,

tacit knowledge,

Subject-to-Subject approach.

\begin{abstract}
A B S T R A C T
This paper presents the results of qualitative study aimed to explore the relationship between the perception of behaviors that support people development, core coaching competences and values supporting them, and wisdom-related values. Our hypothesis was that the reflection on empowering behaviors focuses managers' attention on wisdom-related values that are very close to the core values of coaching and therefore facilitate their progress towards wisdom-related performance. Sample consisted of 306 managers $(\mathrm{N}=306)$ interviewed in 28 groups $(\mathrm{N}=28)$ within leadership development programs in Russia, Ukraine and France from 2008 to 2016. We used the open-ended questions method and qualitative content analysis. The results showed high homogeneity of responses and high degree compatibility between behaviors quoted by respondents and the International Coach Federation core competences. In the second part of the study the responses were analyzed from the point of view of beliefs and values that can support desired developmentally focused / coaching behaviors, and compared the outcome with the existing concepts of wisdom. The study confirmed that the professional training in coaching leads to the cumulative development of wisdom (wisdom-related values, wisdom-related knowledge, wisdomrelated performance) because the core of the system of coaching values fundamentally coincide with wisdom-related values.
\end{abstract}

(C) 2016 IJCRSEE. All rights reserved.

\section{INTRODUCTION}

The 4th technological revolution and structural crises bring new challenges both for organizations and leaders. Fast and unpredictable changes in life and business environment raise the demand for emotionally balanced and creative leadership, and have impact on the shifts in educational paradigm and people management.

Traditional paradigm of education,
Corresponding Author
Dr. Mikhail Klarin, Institute for Strategy of Education
Development, Russian Academy of Education,
Moscow, Russian Federation
E-mail: consult@klarin.ru

\section{(i) $\ominus$}

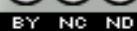

This work is licensed under a Creative Commons Attribution - NonCommercial - NoDerivs 4.0. The article is published with Open Access at www.ijcrsee.com centered on academic knowledge, traditional teacher-student model of education, with value and focus on collecting knowledge, is getting replaced by developmental paradigm with the idea of transforming experience and/or environment (Klarin, 2016b, Bard and Soderqvist, 2002). Another relevant trend that affects educational paradigm is related with the need to distinguish relevant information from insignificant in the huge and daily multiplying flow of data (Saganenko, 2001). The idea of individual knowledge is also far more often than ever challenged by collective thinking idea.

In past decades development of leaders implied enough time to experience different situations and learn from them. Modern time requires high speed for reactions and decisions that prevents leaders from obtaining natural wisdom by conventional means. The profession of coach emerged as the reaction on the need to faster peoples' maturation: “... 
the highest purpose for coaching in troubled times must be to make the leader's implicit wisdom resources more explicit and to help them shape those resources into a personal 'compass' to make wise decisions in the service of a common good" (Klarin, 2015).

It is also highly relevant that nowadays the need for life-long learning is combined with the need for very fast learning. On top of that in many situations where learning is involved, there are no patterns of experience ready to be presented, explained, or taught. The idea of taking long time to adapt pieces of experience for educational transfer often becomes obsolete (Klarin, 2015).

Here come new individual and collective knowledge generative practices such as coaching, facilitation, and moderation that emerged comparatively recently, and already became professional activities and favorable skills for leaders.

Among generative practices coaching is a professionally guided practice that models the key competences of people who empower the growth and development of other people, inspire cooperation and accelerate the progress from reactivity to proactivity, and practical wisdom.

The goal of this study was to explore a relationship of perception of behaviors that support people development and core coaching competences, and to find out what are the values that support such behavior.

The objectives were:

1) to find out if the wisdom related behaviors appear during the experience reflection done by managers;

2) to classify the outcome of this field work applying content analysis;

3 ) to discover the relation between the major development supporting behaviors with the ICF core competences content and wisdomrelated values.

Thus, this was a qualitative study rather than a statistically based quantitively based research.

\section{MATERIALS AND METHODS}

Who can be a good role model for leader or the new reality? Of course, the first idea that comes to data driven and knowledge oriented mind is to dive deep into the reading the articles, books and whitepapers.

Experientially focused developmental paradigm inspired us to ask directly those who experience working with many people and various leaders daily, percept their behavior and its impact on them, who can reflect on the best experience in this area, and then utilize the live learning gathered to transform their own behavior as managers and leaders.

Our hypothesis was that the reflection on empowering behaviors focuses managers' attention on wisdom related values that are very close to the core values of coaching and therefore facilitate their progress towards wisdom related performance.

Inspired by P. Webb saying “... wisdomrelated knowledge may be latent in people until activated by wisdom task..." (Saganenko, 2001) we decided to check if leadership and coaching skills training for managers based on authority and wisdom concepts can lead to the focus on wisdom related behavior and performance, wise knowledge and values, and therefore stimulate the cumulative development of wise behavior in the communication and people development.

Since 2008 within the corporate leadership development programs for the top and middle management we regularly asked the leaders do the reflective analysis related to their experience of empowering authority. There were 28 groups with total number of 306 participants observed in Russia, Ukraine and France.

The participants working in the groups of 7-14 people were asked to meditate briefly on the following question and share the insights: "Please recall the person or several people who you have perceived and currently perceive as the authority for you, those with whom you have reached the top results in your professional activities and personal achievements. Recall, what exactly these people did or do, that supports your fast growth both personally and professionally". The summary list generated by the group was used as the reference point for further selfassessment and ideas list for the individual development plan.

The material collected was processed applying qualitative open-ended questions method (Mayring, 2000) and further qualitative content analysis (Banicki, 2009).

As a result of this study, we discovered the explicit correlation of the data received with two interrelated domains: coaching competences and the concept of wisdom.

\section{RESULTS}

Our first discovery was that results received in each group have been highly ho- 
mogeneous irrespective of industry (FMCG, banking, heavy industry and mixed groups observed) and the age of respondents.

There was a clear list of behaviors that come regularly within all the groups and among those 30 behaviors of empowering authority people 25 items were compatible with the coaching core competences developed by the International Coach Federation (ICF).

Here is the list of these behaviors grouped in alignment with the competences. We quote the most often wording that respondents used describing the behaviors.

The first significant group of behaviors was compatible with the competence 3 - "Establishing Trust and Intimacy with the Client - Ability to create a safe, supportive environment that produces ongoing mutual respect and trust". In the study, corresponding responses included:

1. Treat you as an equal, do not put themselves above another person.

2. Walk the talk - their words are aligned with their actions. sibility.

3 . In case of failure they accept respon-

4. Support me and the team in difficult/ critical situations.

5. Notice when I feel bad, and support.

It is important to mention that all the 11 competences have the detailed explanation and markers that either sounded very similar or could be perceived as rephrasing to the words used by the respondents while they explain what they mean when they name certain behavior. E.g. for item 4 participant said: "She knew that it was difficult task for me and many times encouraged me to relax and focus on what I can learn doing this. She said that the only one who doesn't make mistakes is the one who never does anything", - compare with: coach "Provides ongoing support for and champions new behaviors and actions, including those involving risktaking and fear of failure".

The second big group was compatible with the competence 4 - "Coaching Presence - Ability to be fully conscious and create spontaneous relationship with the client, employing a style that is open, flexible and confident". In the study, corresponding responses included:

6. Not afraid to say that they do not know something, keen to learn. riosity.

7. Try new working methods with cu-

8. Have a good sense of humor.

9. Know how to laugh at themselves.
10. Keep calm and reasonable in critical situations and help others to cool down.

Comparing them with details of coach expected behaviors for this competence we found the impressive similarity in wording: "Is open to not knowing and takes risks", "Confidently shifts perspectives and experiments with new possibilities for own action", "Sees many ways to work with the client and chooses in the moment what is most effective", "Uses humor effectively to create lightness and energy", "Demonstrates confidence in working with strong emotions and can selfmanage and not be overpowered or enmeshed by client's emotions".

The third relevant group referred to behaviors linked with competence 5: - "Active Listening - Ability to focus completely on what the client is saying and is not saying, to understand the meaning of what is said in the context of the client's desires, and to support client self-expression". In the study, corresponding responses included:

11. Know how to listen.

12. Don't like to give advice and ready solutions, but instead they force me to think on my own.

13. Carefully analyze situations and mistakes.

14. Do not accuse, but help me to understand the situation, if something goes wrong.

While leader "Does not accuse, but help me understand the situation, if something goes wrong" (item 14), coach "Allows the client to vent or "clear" the situation without judgment or attachment in order to move on to next steps", "Summarizes, paraphrases, reiterates, mirrors back what client has said to ensure clarity and understanding", and "Encourages, accepts, explores and reinforces the client's expression of feelings, perceptions, concerns, beliefs, suggestions, etc."

The fourth group was compatible with competence 7: "Direct Communication - Ability to communicate effectively during coaching sessions, and to use language that has the greatest positive impact on the client". In the study, corresponding responses included: public.

15. Give feedback personally and not in

16. Explain the logic of their actions.

17. Explain their decisions.

This competence requires coach "Is clear, articulate and direct in sharing and providing feedback", "Reframes and articulates to help the client understand from another perspective what he/she wants or is uncertain about", "Clearly states coaching objectives, 
meeting agenda, and purpose of techniques or exercises".

The fifth group was found out to be related with the competence 9 - "Designing Actions - Ability to create with the client opportunities for ongoing learning, during coaching and in work/life situations, and for taking new actions that will most effectively lead to agreed upon coaching results". In the study, corresponding responses included: tasks.

18. Entrust me interesting and difficult

19. Notice my successes and progress.

20. Rejoice when I succeed.

The sixth group was compatible with competence 8 - "Creating Awareness - Ability to integrate and accurately evaluate multiple sources of information and to make interpretations that help the client to gain awareness and thereby achieve agreed upon results". In the study, corresponding responses included: perience.

21. Allow me to learn from my own exsomething.

There were also single answers were compatible with other competences. It was interesting for us that these competences are usually perceived as most typical for coaching when new clients describe it.

Competence 6 - "Powerful Questioning - Ability to ask questions that reveal the information needed for maximum benefit to the coaching relationship and the client". In the study, corresponding responses included:

23. Ask tough questions that help in looking at the situation from different angles.

Competence 10 - "Planning and Goal Setting - Ability to develop and maintain an effective coaching plan with the client". In the study, corresponding responses included:

24. Help in setting up clear goals and objectives.

Competence 11 - "Managing Progress and Accountability - Ability to hold attention on what is important for the client, and to leave responsibility with the client to take action". In the study, corresponding responses included:

25. Do not perceive mistakes as a disaster and help to fix them.

Two other groups of the behaviors that do not correlate with coaching competences can be viewed as traditional educators' behaviors. In the study, corresponding responses included:

26. Have wide experience and generously share it.
27. Generously share information.

28. Explain what you did wrong and help to understand how to act differently.

And team leader's behaviors. In the study, corresponding responses included:

29. Being team leaders they do not arrogate the results in case of success, they share it with the team and emphasize the contribution of each team member.

30. Act equitably.

It was also interesting for us that the word "wisdom" appeared rarely per se but most of the behaviors could be attributed as wisdom related behaviors based on all existing models of wisdom (Kunzmann and Baltes, 2005; Stacke, 2001).

The analysis clearly confirmed that behaviors that can be attributed as coaching related, being perceived without coaching framework, when it is demonstrated regularly, is perceived as supporting people in their learning and development, and creating the atmosphere that helps them overcome the frustration linked to difficult tasks, uncertainty and challenges, and switch to focused and more creative working mood.

\section{DISCUSSION}

This impact of coaching culture on the atmosphere and performance in the organization serves as a trigger for increasing implementation of coaching and growing investment into developing coaching culture in organizations (Clutterbuck and Megginson, 2006, Baltes and Smith, 1990). In the corporate environment, the predominant task of coaching is leadership development, and the proportion of these cases is growing steadily.

In the second part of our study we analyzed the responses from the point of view of beliefs and values that can support desired developmentally focused / coaching behaviors, and compared the outcome with the existing concepts of wisdom (Kunzmann and Baltes, 2005; Sternberg, 1998; Brugman, 2006).

Although wisdom is often perceived as the product of age, currently wisdom is far more often perceived as emerging in the course of learning from life (Sternberg, 1998).

Our choice of wisdom as a core concept was motivated by the growing interest to tacit knowledge underling wisdom as a basis for high and sustainable efficiency in turbulent times (Sternberg, 1998; Choukhno, 2009; Klarin, 2016a, Klarin, 2015).

The domain of wisdom covers both in- 
telligence and personality. It is also clearly related to adult development and the transformation of beliefs and values as a result of reflection on life events and relevant experience. Most of the researches exploring the domain of wisdom paid high attention to the values that shape the wise behavior.

Analyzing our data, we found 6 key beliefs related to such values that help leaders apply developmental and educational approach in their day-by-day practice: portunity.

1. Every situation provides learning op-

2. Supporting development every day is good for both people and organization.

3. Empowerment stimulates, rewards and pays back as people become more proactive.

4. People are equal; although we can play different roles all people deserve respectful communication.

5. Awareness and feedback matter and help in achieving top results.

6 . Work itself can be an inspiration; people are most productive when they are happy and can enjoy what they are doing.

This list we found coherent with the core values for coaching (Buber, 1958) that are the following:

Awareness;

Proactive life attitude (in a solution of personal, professional, and business objectives);

Responsibility;

Reflexivity and understanding of the performance;

Co-learning attitude (Subject to Subject, Vs. Subject to Object attitude);

Dialogue based;

Non-prescriptive interaction.

A defining characteristic of coaching as a profession is its focus on developing human potential and resources for better decision making and improving the quality of action. This requires global shift of perception of other person as an 'Object' for development to building communication with the person as the 'Subject' - equally knowledgeable and responsible person (Klarin, 2014; Webb 2008).

The importance of Subject-to-Subject approach in stimulating wisdom related behavior was unexpectedly confirmed by the fact that $50 \%$ of responses received during our study had focus on 3 competences: Establishing Trust and Intimacy, Coaching Presence and Active Listening, which help coach create and support Subject-to-Subject dialogue where knowledge and values of client are respected and activated for further transformation.

Following P. Webb (Kunzmann, Baltes, 2005) we concentrated our attention on several approaches to wisdom, which have major relevance to coaching:

1. Wisdom as a system of expert knowledge in Berlin wisdom paradigm (Ardelt, 2004).

2. Wisdom as a property of a person not reduced to expertise (Sternberg, 2005).

3 . Wisdom as interaction between person, task and situation - wisdom, intelligence, and creativity, synthesized (WICS) (Kilburg, 2000).

4. Wisdom as a "mapping" process (Baltes and Smith, 1990).

Within the Berlin wisdom paradigm, which includes five criteria we found a solid basis to our research. Here are these criteria:

1. Rich factual knowledge (possession of 'an extensive data base about life matters'),

2. Rich contextual knowledge (a repertoire of mental procedures (or heuristics) used to select, order, and manipulate the information in the data base and to use it for the purposes of decision making and action planning),

3. Life span contextualism (relating knowledge to "the many themes and contexts of human life', and 'their interpretations and cultural variations'),

4. Value relativism and tolerance (relating to 'acknowledgement of individual and cultural differences'),

5. Recognition and management of uncertainty (relating to 'knowledge about the limits of knowledge and the uncertainties of the world' (Webb, 2008).

As for wisdom in leadership, the definition suggested by P. Webb includes the following components: (a) the application of the five wisdom criteria of the Berlin wisdom paradigm, drawing from tacit knowledge and personality characteristics (cognitive, reflective and affective), (b) through the acknowledgement of core values, (c) balancing the interests of self, stakeholders and the organizational community, (d) by adapting, shaping or selecting appropriate responses, (e) in order to achieve a sustainable good (Webb, 2008).

The present study shows that relativism and tolerance combined with recognition and management of uncertainty based on wise values helps leaders, coaches and coachcompetent young managers behave reasonably and make wise decisions under pressure.

This study shows that rich factual and contextual knowledge together with life span 
contextualism correlated with educator's behaviors is perceived and accepted by young managers supported by coaching Subject to Subject attitude.

\section{CONCLUSIONS}

This study leads to the conclusion that the wisdom-related knowledge and wisdomrelated performance are based on wisdomrelated values that can be comprehended by reflection on role models and applying the learning via modeling correlating behaviors.

As the managers are trained in valuerooted coaching behaviors, they compare and transform their perception of their routine and environment, and develop wiser and more mature attitude towards life and other people.

Such core competences as Coaching Presence, Creating Trust and Intimacy, and Active Listening being based on wisdom related knowledge allow leaders treat people as equal, smart, able and responsible, and open trigger access to tacit knowledge.

It means that we can consider and employ coaching wider than just a technology for improving performance but as a wisdom empowering approach that supports and expands developmental paradigm of the new era.

Using significant wisdom-related components shared in coaching and leadership approach we can make it a cultural tool, a tool that will make the wisdom of the present a widely shared legacy of the new generations.

\section{ACKNOWLEDGEMENTS}

This study was supported by Nova Terra Coach Training \& Corporate Development team, our colleagues from the International Coach Federation (ICF) and the Association of Russian-Speaking Coaches (ARC), and we would like to thank them for the support in discussing ideas. We are very grateful to our colleagues Alla Kuznetsova, Alla Chuhno and Alexei Ionov who had supported us in gathering the field data for the study and shared their ideas on the outcome. Special thanks go to Sir John Whitmore whose exercise during coach training in Moscow inspired us to dig deep into the links between developmental management, wisdom and coaching competences.

\section{Conflict of interests}

Authors declare no conflict of interest.

\section{REFERENCES}

Ardelt, M. (2004). Wisdom as expert knowledge system: A critical review of a contemporary operationalization of an ancient concept. Human development, 47(5), 257-285. doi:10.1159/000079154

Baltes, P. B., \& Smith, J. (1990). Toward a psychology of wisdom and its ontogenesis. Wisdom: Its nature, origins, and development, 1, 87-120.

Banicki, K. (2009): The Berlin Wisdom Paradigm: A Conceptual Analysis of a Psychological Approach to Wisdom, History \& Philosophy of Psychology, 11(2), 25-35. https://philpapers.org/ $\mathrm{rec} / \mathrm{BANTBW}$

Bard, A., \& Söderqvist, J. (2002). Netocracy: the new power elite and life after capitalism. Pearson Education.

Brugman, G. (2006). Wisdom and aging, J. E. Birren, W. Schaie, and R. P. Abeles (Eds.), Handbook of the psychology of aging, 6th ed., San Diego, CA: Academic Press, 445-476.

Buber, M. (1958). I and thou (R. Gregor Smith, trans.). New York, NY: Scribner.

Choukhno, J. (2009). Coal and Mud or Dimonds and Truffels? Human capital in crisis period. Monthly scientific-practical journal "Psychotherapy" 9, 9-18. (in Russian).

Clutterbuck, D., Megginson, D. (2005). Making coaching work: Creating a coaching culture. CIPD Publishing. http://www.coachfederation.org/ credential/landing.cfm?ItemNumber $=2206 \& \& n$ avItemNumber $=576$

Clutterbuck D., Megginson D. (2006). Making coaching work: creating a coaching culture. London: CIPD.

Kilburg, R. R. (2000). Executive coaching: Developing managerial wisdom in a world of chaos. American Psychological Association. http://dx.doi. org/10.1037/10355-000

Klarin, M. V. (2014). Glossary: a dictionary of terms used in the professional standard "Coach". Organizational psychology, 4(1), 87-89. https:// orgpsyjournal.hse.ru/data/2014/07/22/1310902 120/2014 1 14(Глоссарий)87-89.pdf

Klarin, M. (2015). The New Educational Practice of Coaching, and the New Profession of the Coach. Russian Education \& Society, 57(6), 415-428, doi:10.1080/10609393.2015.1096131

Klarin, M. (2016a). Transforming adult learners' experience in corporate context: conceptual paradoxes and pragmatic conclusions. In SHS Web of Conferences (Vol. 29). EDP Sciences. International Conference "Education Environment for the Information Age" (EEIA-2016). Moscow, Russia, http://dx.doi.org/10.1051/shsconf/20162901033

Klarin, M. (2016b). Conceptual challenges in understanding innovative education in organizational context. International Journal of Cognitive Research In Science, Engineering And Education (IJCRSEE), 4(1), 67-72. doi:10.5937/ IJCRSEE1601067K

Kunzmann, U., \& Baltes, P. B. (2005). The Psychology of Wisdom: Theoretical and Empirical Challenges, In Sternberg, R., \& Jordan, J. (Eds.). A handbook of wisdom: Psychological perspectives. Cambridge University Press, 110-135

Mayring, P. (2000). Qualitative Content Analysis. Forum Qualitative Sozialforschung / Forum: Qualitative Social Research, 1(2). http://www. 
qualitative-research.net/index.php/fqs/article/ view/1089/2385

Saganenko, G. (2001). Systems, formates and cognitive potential of open questions, Journal of sociology and social anthropology, IV: 4, 171-194. (in Russian).

Stacke E. (2001). Coaching d'entreprise. Paris: Village Mondial.

Sternberg, R. J. (1998). A balance theory of wisdom. Review of general psychology, 2(4), 347-365. http://dx.doi.org/10.1037/1089-2680.2.4.347

Sternberg, R. J. (2005). WICS: A Model of Leadership. The Psychologist-Manager Journal, 8(1), 29-43. http://dx.doi.org/10.1207/s15503461tp$\operatorname{mj} 08014$

Webb, P. J. (200̄8). Coaching for wisdom: enabling wise decisions. D. B. Drake, K. Gørtz, D. Brennan (Eds.). The Philosophy and Practice of Coaching. San Francisco, CA: Jossey-Bass, 161-175. https://ssrn.com/abstract $=1617789$ 